ON

\title{
DISEASE OF THE KIDNEY,
}

ACCOMPANIED BY

\section{ALBUMIN URIA.}

(SECOND PAPER.)

BY

W. H. DiCKInson, M.B. Cantab., MEDICAL REgISTRAR AND DEMONSTRATOR OF ANATOMY AT ST. GEORGE's HOSPITAL, AND ASSISTANT-PHYSICIAN TO THE HOSPITAL FOR SICK CHILDREN.

Received March 20th.-Read May 28th, 1861.

IN a paper printed in the last volume of the ' Transactions' of this Society, I examined pathologically those alterations of the kidney which have been loosely described as Bright's disease. I endeavoured to show that there are two essentially different diseases which have been so denominated. One, which is characterised by increase of bulk, the surface remaining smooth, is owing to an inordinate secretion within the tube. This, in its nature, is nephritis, or, to apply the language of Dr. Prout, "hæmotrophy ;" I therefore may be permitted to use the terms chronic nephritis, tubular disease, and smooth, mottled kidney, as synonymous. The other disorder produces for the most part diminution of size, renders the surface uneven and granular, and is the result of an affection of the intertubular structures. This is rather a degenerative than an inflammatory condition, and, after Dr. Prout, may be termed anæmotrophy. 
I now propose to complete my sketch of the disease by filling in the clinical details, showing how, during life, the one disease may be distinguished from the other, and how far the conclusions based upon morbid anatomy are warranted by what is observed before the death of the patient.

I have extracted from the ample records of St. George's Hospital the particulars of every well-defined case of either of these disorders that was examined in the dead-house during ten consecutive years. The total number of "postmortems" in this period was 2350, in 250 of which the kidneys were granular, in 119 smooth and mottled. An analysis of these cases may be trusted for certain deductions, while other particulars will be drawn from cases under my own observation in the wards, making use only of those in which the state of the kidney has been attested by postmortem examination.

It will be convenient to ascertain, first of all, the sex, age, and constitutional tendencies of the persous affected with either of these disorders.

They both occur more often in the male than in the female sex. Out of the 119 cases of the smooth kidney just alluded to, there were 87 males to 32 females, a proportion of nearly 3 to 1 . With regard to the granular kidney, the preponderance is on the same side, though to a rather less extent. The 250 cases were distributed between the sexes in the proportion of 165 male to 85 female, or very nearly 2 to 1 .

There is a great difference as to the age which each selects. The accompanying tabular statement will sufficiently show that the tubular disease chiefly affects the earlier periods of life, occurring even in infancy ; that it is most frequent between the ages of twenty and thirty, while old age is nearly exempt from its attacks.

The granular kidney is distributed in inverse proportion; it chooses that portion of life which is untouched by the other. No instance was met with before the age of eighteen. It is most common between forty and fifty, and sometimes is seen even at the most advanced periods of existence. 
Table, showing the ages at which the two diseases terminate.

\begin{tabular}{|c|c|c|c|c|c|c|c|c|c|}
\hline & \multicolumn{9}{|c|}{ AGES, IN YKARS. } \\
\hline & 1 to 10. & 11 to 20. & 21 to 30. & 31 to 40 . & 41 to 50. & 51 to 60. & 61 to 70. & 71 to 80 & 81 to 90 \\
\hline $\begin{array}{c}\text { Nephritis, } 117 \\
\text { cases } \quad \ldots . . .\end{array}$ & 10 & 16 & 39 & 23 & 20 & 8 & 1 & O & 0 \\
\hline $\begin{array}{c}\text { Granular de- } \\
\text { generation, } \\
243 \text { cases }\end{array}$ & o & 2 & 17 & 38 & 73 & 55 & 43 & 12 & 3 \\
\hline
\end{tabular}

Placing the same facts in a different point of view, I may state that in 106 cases the average age at which the smooth kidney, yet uncontracted, appeared in the dead-house, was 28.2 years. Of the rare stage of the disease, where it had led to wasting of the organ, the average, in 11 cases, was 43.6 years. In 250 cases of the granular kidney, the average age was $50 \cdot 2$ years.

These facts, which need no comment, would afford, independently of all other evidence, a strong presumption that the two disorders depend on essentially distinct tendencies.

It appears that there are certain predispositions which favour the development of one disease rather than the other. This is most conspicuous as regards gout, or what is called rheumatic gout, as has already been pointed out by the late Dr. Todd. In 33 cases under my own observation during life, and where, after death, the smooth kidney was found, there was not a single instance of the occurrence of either of these complaints. In the 119 cases spoken of before, there was one mention of gout, and that was doubtful. On the other hand, 31 cases of granular degeneration from my own notes afford no less than 10 with gouty complication; and in the 250 from the postmortem records there was evidence of gout, chiefly in the form of chalk-stones, in 17.

It appears that the gout generally precedes, often by a 
great many years, the development of the renal symptoms. A case where this went on for twenty-six years, and another for twenty, have come under my own notice. Such facts lead to the conclusion that the renal degeneration is caused by the foregoing disorder, or else that both are due to a common cause. If the gout appeared in consequence of the imperfect action of the gland, we should expect to find it in the other form of disease, where the powers of excretion are at least as much interfered with.

It further appears that a tendency to tuberculosis encourages the granular degeneration of the kidney. In 20.8 per cent. of the cases of this complaint some form of tubercle existed in the lungs. With the smooth kidney, although that disorder is most common just when the mortality by phthisis is the greatest, the disease of the lungs existed only in 16.8 per cent. of the cases observed. Regarding the matter from another point of view, I find that, out of 244 cases of phthisis examined during five years in St. George's, 46 had also granular kidneys, while in only 17 were those organs smooth and mottled. Allowing for the correspondence in time of life between consumption and the last-mentioned renal disease, we cannot hesitate to infer that the tuberculous constitution is peculiarly liable to granular degeneration of the kidney, although, of course, it does not confer an exemption from the attacks of nephritis.

Leaving out of the question the argument from morbid anatomy, these facts alone would furnish strong evidence as to the independence of the two diseases under consideration. I will now briefly review the symptoms proper to each, and show at once their points of difference and the means of diagnosis.

The accompanying table, which includes all the cases examined during ten years at St. George's, has been constructed partly from the report of the post-mortem, and partly from the history of the case which is annexed. None of the examinations were made with any especial object, and no doubt all the numbers here given are too low. This must be especially the case with such symptoms as those of bronchitis or of diarrhœa, which, should they escape mention 
in the condensed history of the case, have little chance of being rendered evident by the traces they leave behind them after death.

\begin{tabular}{|c|c|c|}
\hline $\begin{array}{c}\text { - Kxydode } \\
\text { snoวụnours }\end{array}$ & $\stackrel{10}{0}$ & $\stackrel{\infty}{0}$ \\
\hline 'вu00 วүلया!s & 움 & $\begin{array}{l}\infty \\
\dot{\infty}\end{array}$ \\
\hline 'suo!̣s|nıиoo & i & is \\
\hline 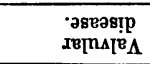 & $\stackrel{+1}{+1}$ & ஸे \\
\hline 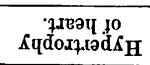 & 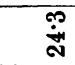 & $\begin{array}{l}\dot{\rho} \\
\dot{\alpha} \\
\dot{q}\end{array}$ \\
\hline 'втохәчҰУ & $\stackrel{\varphi}{\dot{a}}$ & ثั่ \\
\hline 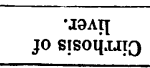 & 官 & $\begin{array}{l}\text { 年 } \\
\text { in } \\
\end{array}$ \\
\hline 's૯[ə]! & i) & 市 \\
\hline s!̣xeqs!d & $\stackrel{\infty}{\dot{0}}$ & $\ddot{\infty}$ \\
\hline 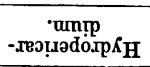 & $\stackrel{m}{\stackrel{N}{*}}$ & $\stackrel{?}{\dot{\Xi}}$ \\
\hline хе.лочұохр $\hat{\Omega}_{\mathrm{H}}$ & $\begin{array}{l}20 \\
\dot{a} \\
\dot{N}\end{array}$ & 㢳 \\
\hline 'sə7! & फ் & 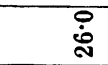 \\
\hline ·вшәрФD & कृ & 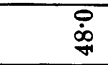 \\
\hline 'ห़̣िoutməu & $\overrightarrow{\dot{\overbrace{}}}$ & 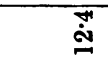 \\
\hline 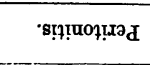 & 営 & ஸ் \\
\hline 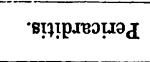 & $\stackrel{5}{+}$ & 㐫 \\
\hline 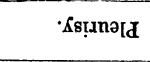 & 品 & 通 \\
\hline 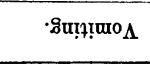 & के & ì \\
\hline вюоपлде! & $\dot{\text { هิ }}$ & $\stackrel{\varphi}{=}$ \\
\hline \multirow[t]{2}{*}{ 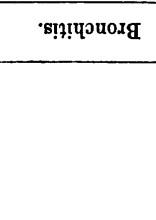 } & $\begin{array}{l}\dot{4} \\
\dot{\infty} \\
-1\end{array}$ & 犬ิ \\
\hline & 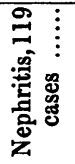 & 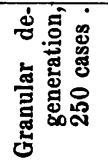 \\
\hline
\end{tabular}




\section{CHRONIC NEPHRITIS.}

I need make no excuse for adopting the comprehensive term nephritis for what has been called the tubular disease, though the inflammatory action is seen rather in its results than its operation. As in bronchitis, so in nephritis; the inflammation may be evinced by simple excess of secretion, or of cell growth, though in the latter case mechanical injury to the organ may result from the accumulation of the epithelium.

This disorder is generally produced by some irritating matter operating on the gland. Spirits of turpentine or cantharides, given medicinally; a spell of hard drinking; bile vicariously eliminated by the kidneys; the poisons of measles and scarlatina passing from the system in the course natural to them; and, above all, by that series of pathological changes known as " catching cold," by which all the materials due to the glands of the skin are suddenly thrown upon the internal glandular organs.

Besides such causes as these, it may have its origin in venous obstruction, such as takes place in successive pregnancies, although the kidney will usually bear venous congestion patiently, as we see in many cases of valvular disease of the heart.

Thus, in thirty-eight cases under my own notice during life, and where the condition of the kidneys was verified by post-mortem examination, the cause was clearly ascertained in twenty-one-

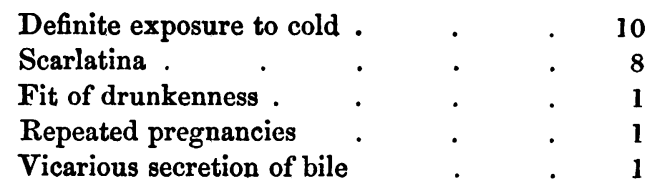

From whichever of these causes the disorder has taken its origin, its commencement is almost always definite. The change in the condition of urine is obvious, and the 
symptoms are such as to command attention-aching in the loins ; the urine scanty, and discoloured with blood; œedema, beginning in the face, and soon pervading the whole body. Hence it is easy in most cases to be quite sure of the duration of the disease as well as of its exciting cause. This is in strong contrast with what is observed with granular degeneration.

Once started, the inflammatory action may cause death in two or three days. The scanty urine, loaded with albumen, blood-globules, and casts of various kinds; the outbreak of dropsy; the termination by coma, and the visible congestion of the kidney after death, furnish a familiar picture of nephritis in an acute form. My purpose is chiefly with the more chronic rarieties of the disorder.

The more the disease is prolonged the more the epithelial growth accumulates, and, by distending the tubes with opaque, white matter, disguises the earlier indications of congestion. When appearing as the sequel of scarlet fever, the characteristic pale colour is sooner produced than when it is a consequence of exposure to cold.

The disease usually runs a slow course, but whether the patient die during the first week or live for a year, the nature of the disorder is essentially the same. In fatal cases the ordinary duration of the disease is under six months. In thirty-four such cases under my own observation, seven terminated during the first month, eight during the second; by the end of six months twenty-six of the whole number were dead, while only two survived the year.

The symptom which is most prominent, and, next to albuminous urine, the most invariable, is dropsy. This, with the peculiar whiteness of the skin, imparts a characteristic physiognomy to the disease. It varies directly with the obstruction in the tubes and the scantiness of the urine. It invades the cellular tissue, the peritoneum, the pleura and the pericardium, with a frequency corresponding to the order in which they are here placed.

The liability of certain structures to become inflamed is 
the most serious character of the disease. More cases die from this cause than from any other. Pleurisy is by far the most common result; then inflammation of the pericardium, peritoneum, lungs, and bronchial tubes, in the order mentioned. The comparatively great frequency of peritonitis and pneumonia, and the comparative rarity of bronchitis, constitute a point of difference between the disorder at present under consideration and granular degeneration.

Vomiting is more frequent than diarrhœa. It may occur at any stage of the complaint, even at the outset. Diarrhœa, although not diagnostic of the disease, is greatly more frequent than with granular degeneration, even more so, according to my own experience, than the foregoing table shows. It comes on in cases of some standing, it generally causes the dropsy to subside, and often occasions the death of the patient by the exhaustion which results.

Pain in the loins is a symptom of considerable value, as a means of distinction between one and the other disorder. It accompanies most examples of the complaint now under consideration, while it is very rare as a result of the more chronic disease. A converse statement may be made with regard to a less serious inconvenience. Frequency of micturition seldom accompanies the smooth, mottled kidney, while it is seldom absent from the granular. This symptom, as has been observed by Dr. Prout, is most marked when the patient is in the horizontal posture.

With regard to the "head symptoms" in connection with this disorder, though it is not uncommon for acute cases to lapse gradually and quietly into a state of coma, yet in the chronic form the final coma seldom appears except as the sequel of epileptic convulsions, though these often occur and pass off without any immediate evil. They are often foretold by pain in the head, and are, as has been pointed out by Dr. Bence Jones, especially apt to come on in persons who suffer from vomiting and diarrhœe, as if these symptoms are promoted, if not produced, by an anæmic state of brain. It also appears that patients who 
have been taking stimulating diuretics, such as tincture of cantharides, are particularly liable to be so affected.

When it is considered that almost all the symptoms I have enumerated are very indirect consequences of the disease, a high value will be attached to the direct evidence of the state of the kidney which is furnished by the urine.

This is usually diminished in quantity ; at first invariably so. During the more advanced stages of the disease, or as a temporary attack is passing off, it sometimes becomes more than naturally profuse.

It is acid in the great majority of cases; when alkaline or neutral, it is under the conditions mentioned as increasing the quantity of the secretion. Uric acid crystals and urate of soda are often present.

It is discoloured with blood in a large proportion of cases, especially at the outset; the more so the more acute the affection. If the mixture present a pink tint, instead of the usual smoky or cairngorm colour, this is due.not to any peculiarity in the hæmorrhage itself, but to the want of acidity in the urine.

The albumen is almost always considerable, the coagulum bulky in proportion to the quantity of urine tested; the fluid sometimes even gelatinous when boiled.

The specific gravity varies greatly, ranging between 1010 and 1030, or even more widely ; in the majority of cases, however, departing little from the limits of health. Thirtyseven cases, attested by post-mortem, where the urine was repeatedly examined during life, gave an average of 1019 .

The microscope is more useful in confirming a diagnosis formed upon other evidence, than as an independent guide. It is usual to find, especially in the earlier stages of the renal catarrh, a large deposit of loose epithelium. As the disease progresses this may undergo a metamorphosis into pus, or the cells may become charged with oil globules. These alterations of course correspond with like changes within the secreting tubes. The phase of chronic nephritis indicated by the shedding of fatty epithelium, runs a course so parallel to the cases where no such degeneration takes place, that it 
can only be discriminated during life by the microscopic examination of the urine, and no clinical division has been here attempted. It appears to be particularly apt to occur in such cases as owe their origin to cold ; and is of course an unpromising complication. That the tissues of the body should become fatty under the influence of inflammatory action is what daily experience teaches.

Casts of the tubes are almost always present in the disorder now under consideration. The fibrinous exudation which forms their basis is derived chiefly from the cones, as is evident from the fact that after death it is often seen filling the tubes in this portion of the organs, while none is seen elsewhere. The cylinders found in the urine are therefore, strictly speaking, casts of the straight tubes, though some of their materials may be furnished by other portions of the gland. The nature and quantity of the epithelium passing from the secreting tube, and the absence or presence of hæmorrhage, will of course be indicated by their variations.

The casts found in this disorder-and indeed casts in general-may be thus classified:

1. Transparent, glassy cylinders, usually narrow and uniform, though sometimes dotted with minute oil globules.

These may occur as the result of a passing attack of congestion in a kidney otherwise healthy. They appear in all stages of the complaint, whenever, either from the cessation of the morbid action, or from being immoveably plugged up, the secreting tube fails to discharge its epithelial growth.

2. Similar fibrinous cylinders imbedding in their interior cells of such epithelium, natural, fatty, or puriform, as the tubes produce.

These cell-casts are hardly ever absent from the commencement of the renal catarrh. Their frequency lessens as the disease continues, though they are sometimes seen even in the latest stages.

3. Casts containing disintegrated epithelium irregularly mingled with the fibrinous basis. These are more or less dense, according to the proportions in which their elements 
are mingled. They have a finely granular or powdery aspect.

These are really of the same materials as the preceding, differing only in the disintegration of the cells. The state of epithelium which they indicate has already been fully discussed. They may appear in almost any stage of the disease, since all that is required for their production is that the epithelial cells be retained in the duct long enough to lose their form.

4. When blood is passing from the Malpighian tufts the casts already described are diversified with entire blood discs; or the cylinders have a rusty brown colour, and coarsely granular appearance, showing nothing in their interior but disintegrated or compacted corpuscles.

These lend no further aid to the diagnosis than by certifying that the smoky tint of the urine is due to blood poured out by the kidney.

In many cases of the disorder all the variety of casts here mentioned may be found, either at the same time, or in quick succession. None of them are absolutely pathognomic of the disease, rare though it be to find either the uniform cylinders (1), or the cell-casts (2), when the kidney is in a state of granular degeneration.

\section{GRANULAR DEGENERATION.}

This disorder, the result, as has been already shown, of gradual changes originating in the intertubular tissues of the kidney, creeps on, insidiously invading first the outer surface, working its way inwards, and gradually involving and rendering useless one part of the gland after another, until what remains of the organ is insufficient for the wants of the system. Whether the primary alteration of tissue, which is the starting point of the disorder, is as it appears to be, one of those obscure changes of nutrition known as chronic inflammation, or whether the alteration is better described as degenerative, is of little consequence; the 
effect is equally irremediable. It appears to be the result of some hereditary or acquired constitutional vice which gains ascendancy with advancing years. The symptoms are due not to the presence of any active process which admits of control by remedial means, but to the actual destruction of certain portions of the organ, and the necessary impairment of much that remains. Not only are large portions of the secreting tubes destroyed, but, as I have shown in a former paper, the large blood-vessels of the gland are of greatly diminished capacity, and the capillary system is rendered impermeable even to a disproportionate extent. Such alterations in the structure of the organ are, almost necessarily, of slow development, and as they proceed the system becomes accustomed to the deficiency. The gradual change from health to infirmity, and the very tardy appearance of any obvious manifestations of renal disease, correspond to the slowly increasing incapacity of the gland.

This disorder is scarcely ever attributed, even by the sufferer, to any external cause. In thirty-one cases, proved after death to have had this form of disease, the illness was not traced to any definite origin in a single instance; strongly contrasting in this respect with what is observed in the other form of disease.

The patient first seeks advice, it may be, in consequence of some œdematous swelling. It may appear, on inquiry, that for months past he has noticed some fulness or swelling of the ankles on going to bed, that for a long time before the urine had been pale and copious, and had been passed with frequency, especially during the night. It may, perhaps, have been noticed by the patient's friends that his complexion was becoming sallow and his features sharp.

The indefinite nature of its accession makes it difficult to limit the duration of the disorder with anything like the same certainty as we can limit that of the tubular disease. In twenty-one only of my cases was it possible to fix with any accuracy the advent of the first symptoms. One ended fatally in four weeks, this appeared the most acute; eight more at different periods before the end of the first year; 
the remaining twelve going on for a longer or shorter time, up to ten years. It is impossible to say, from these data, how long the disease may last, or in how short a time it may cause the death of the patient. The contrast, however, is sufficiently marked between it and the tubular disease, which generally proves fatal within six months.

The dropsical effusion is often absent for a long time, sometimes altogether. It is rather incidental to the disorder, than, as in the other case, essentially characteristic of it. Of thirty-three fatal cases, no less than twelve were, as far as could be ascertained, without dropsical effusion at any period of the disease; and in only eight had this symptom attained any considerable extent. It is seldom or never found to accompany the earlier stages of the disorder when the urine is unnaturally profuse. The patients, therefore, are widely different in appearance from the victims of chronic nephritis; the bloated aspect and ivory pallor peculiar to the latter disease, contrasting with the withered appearance and sharpened features of granular degeneration, though there may be a little puffiness under the eyes, and a muddy or buff-coloured skin. Possibly the dark hue of the face may be owing to the deficient elimination of colouring matter in the urine.

With regard to the proneness to inflammatory attacks, the comparative rarity of peritonitis, pleurisy, and pneumonia is counterbalanced, as already pointed out, by a greater liability to bronchitis, which is much more frequent than the post-mortem records show. Pericarditis appears to be more impartial, frequently occurring in conjunction with the disease under consideration.

In the earlier part of the paper I adverted to the unusual occurrence of diarrhœa, as well as of lumbar pain. I also made mention of the increased frequency of micturition, which, indeed, often gives the first indication of organic change. I therefore need not dwell further upon these particulars.

The numbers in the table previously given, will suggest an inquiry as to the association of renal disorder with 
valvular disease of the heart. A reference to Dr. Barclay's paper in the 'Transactions,' of this Society (vol. xxxi), will show, that taking death from all causes, valvular disease is present in 18.8 per cent. Now it appears from the calculations, of which the results are given (page 173), that in 43.2 per cent. of the cases of granular degeneration, there also exists a morbid state of the valves of the heart, which is more than double the standard proportion. Regarding the matter in another light, it appears from Dr. Barclay's statistics, that of seventy-nine cases of valvular disease, the kidneys were granular in twenty-nine, or in the ratio of 36.7 per cent.; while it results from the facts given at the beginning of this paper, that reckoning all the cases in the dead-house in ten years, granular degeneration of the kidney is present in the proportion of 10.6 per cent. only. The companionship of the two diseases is therefore more frequent than can be attributed to accidental concurrence, and must be held to show the existence of some bond of union between them.

With the smooth mottled kidney the connexion is less evident, though of course allowance must be made for the early age at which this disease proves fatal. The foregoing table gives $17 \cdot 4$ as the rate per cent. at which valvular disease accompanies this form of kidney, which is less than the standard proportion ; while Dr. Barclay shows that in seventynine cases of valvular disease there were but five of the smooth, mottled kidney. This gives a proportion but slightly greater than holds with regard to all causes of death.

It therefore has to be settled which is the starting point in the series; whether the valvular disease of the heart engenders granular degeneration of the kidney or the converse. A full discussion of this question would occupy more space than can here be accorded, but it may be admitted that the venous congestion consequent upon cardiac derangement, though able to produce, as Dr. Jenner has shown, a certain hardening and toughening of the gland, involving intersticial fibrinous exudation, and ultimately a granular 
surface, is by no means a frequent cause of renal disease. Independent disease of the kidney, on the other hand, with the deterioration of blood which ensues, increases the liability to atheroma, and also appears to be a frequent cause of inflammatory affections of the lining membrane and valves of the heart, as of the pericardium and other structures.

Dr. Bright discovered that renal disease was ordinarily accompanied by simple hypertrophy of the left ventricle, and suggested an explanation which has been further worked out by Dr. Johnson, and appears satisfactory. The blood, altered in character by the imperfect elimination of effete materials, requires more than ordinary force to drive it through the capillaries of the body. The hypertrophy of the heart, therefore, is a result of the increased demand for expulsive power. This adjustment is necessarily a work of time, and is therefore far more frequent with granular degeneration than with the more rapidly fatal disease.

Another development of the same chain of circumstances may be witnessed in the tendency to extravasation of blood within the cranium. Of $\mathbf{2 5 0}$ fatal cases of granular degeneration, seventeen were proved to have been thus affected. The proportion may not appear large, but it is necessary to take into account that granular degeneration of the kidney is one of the most common of the diseases to which flesh is heir, while sanguineous apoplexy is really one of the most infrequent. It is more fatal to the individual than formidable to the race. The period which afforded the 250 cases of granular kidneys, of which I have spoken, yielded but thirty-six of apoplexy. As this number seems too small to give a trustworthy result, I have taken into account a further period of ten years. From this it appears that during twenty years, seventy-five cases of sanguineous apoplexy have been subjected to examination in the deadhouse of St. George's. Thirty-seven of these, or about half, had also decided renal disease. In thirty-one the kidneys were granular; in three large, smooth, and mottled; in three smooth and mottled also, but in the ultimate stage of con- 
traction. We must infer from these data that disease of the kidneys promotes a tendency to rupture of the cerebral blood-vessels. This may be supposed to depend either upon increase of pressure on the inner surface of the arteries, or upon loss of tenacity in their walls; and there is reason to believe that both these conditions concur. There is evidence of the former in the constant occurrence of hypertrophy of the heart, as has been already shown; and of the latter, in the increased frequency of atheroma of the arteries in cases of granular kidneys. In a post-mortem examination, made as those I have quoted have been, with a view to general observation rather than to any especial object of research, nothing would be more likely to elude remark than atheroma of the blood-vessels, yet this condition was noted in more than half of the cases (52.4 per cent.) And of those seventeen who died by way of apoplexy, atheroma was noted in all but three.

Extravasation within the cranium, however, is not the most common of the head symptoms which occur in connexion with the granular kidney. Epileptic convulsions are incidental to this form of disease, though not so frequent as in the tubular disorder already described. But it appears to be characteristic of this variety of renal disease, as compared with chronic nephritis, that patients are very apt to pass gradually into a comatose state, without convulsions, the change being often preceded by dimness of sight, giddiness, peculiarity of manner, or delirium.

The urine is generally increased in quantity in this disorder. It is scanty only in the later stages. This affords a valuable means of diagnosis, as with the smooth kidney the exact contrary takes place. The comparative rarity of lithic acid, and especially of lithate of soda, as a deposit, necessarily follows upon the abundance of the urine. Beside this must be noted the deficiency of yellow colouring matter, rendering the secretion paler or whiter than the increase in quantity could account for, as well as the comparatively rare occurrence of hæmorrhage, which, it seems, never takes 
place in the earlier periods of the disease. In thirty-three fatal cases where the particulars were carefully noted during life, this only happened four times to a sufficient extent to discolour the urine. The albumen is often in very minute quantity, and may even be absent altogether. As the organic change advances, it may appear in larger quantity, but even then is seldom enough to yield the bulky precipitates so generally seen with the other forms of disease.

The specific gravity, as might have been supposed, is much below the range of health, varying usually from 1008 to 1020, though sometimes transgressing these limits in both directions. The average of the cases under my own notice proves to be 1014 .

Under the microscope a small quantity of renal epithelium, or a few pus cells, may sometimes be observed ; so that this deposit cannot be regarded as diagnostic of either form of disease. The same may be said of the large granular spheres which are occasionally met with.

Casts appear with considerable constancy in the more advanced periods of the disease, though often when a trace of albumen has indicated its commencement, they are sought in vain. When present they are often characteristic. They may indeed, in a few cases, be of the uniform glassy appearance described in connexion with chronic nephritis, or they may even contain cells of epithelium as usual with that disorder, but such occurrences are exceptional. In the cases to which I have already referred, as under my own notice, there was not a single one where granular casts were absent, if casts were present at all. In the majority they were coarse, dense, and opaque, but if carefully looked into gave evidence of the intermixture of materials-disintegrated epithelium and clear fibrine-already described as their components. These casts, if found in abundant pale urine of low specific gravity, will afford an indication of granular disease of the kidney, which will seldom point wrong. 


\section{SUMmary.}

The following conclusions may be deduced from what has been brought forward.

The smooth mottled kidney is the result of chronic nephritis. This disease may befall any person, the youthful being the most susceptible. It results from cold, from scarlatina, or some similar cause of renal hyperæmia. It begins with marked symptoms, and usually terminates under a year. It is often temporary in its nature, or amenable to treatment.

The granular kidney is the result of a degeneration which is peculiarly apt to take place in gouty or tuberculous persons. It is never seen except in adults, and is most frequent after the age of forty. It commences gradually, and is quite indefinite in its duration. This state of organ is necessarily irreparable.

Chronic nephritis is characterised by dropsical effusion; a great liability to inflammatory attacks affecting the serous membranes and the lungs; diarrhœe, especially in the later stages; pain in the loins, and finally coma preceded by epileptic convulsions. The urine is scanty, often bloody, the albumen abundant, and the specific gravity comparatively high. Casts imbedding entire epithelial cells are characteristic of the disorder.

Granular degeneration is to be recognised by a gradual failure of health, with sharpening of the features, and discoloration of the skin; while dropsy is often absent or of small extent. Frequency of micturition is observed, especially at night, and there is great liability to bronchitis. There is also a tendency to valvular disease of the heart, as well as to extravasation of blood within the cranium. Epileptic convulsions sometimes occur, but a fatal state of semi-coma often comes on without any such antecedent. The urine is increased in quantity except in the later stages, of low specific gravity, and often containing only a trace of 
albumen. The casts most commonly found are of coarse, granular texture.

Postscript.-One of the most conclusive arguments for the independence of the smooth mottled, and the granular kidney, one which should have been more emphatically dwelt upon in the paper, may be found in tracing the results of scarlatina. That disease is familiar to everybody as giving rise to the large white kidney; whereas the author has never seen, nor has he ever heard or read of, a case of granular degeneration which could be fairly traced to this cause. 
(4)

(Q)

(8)
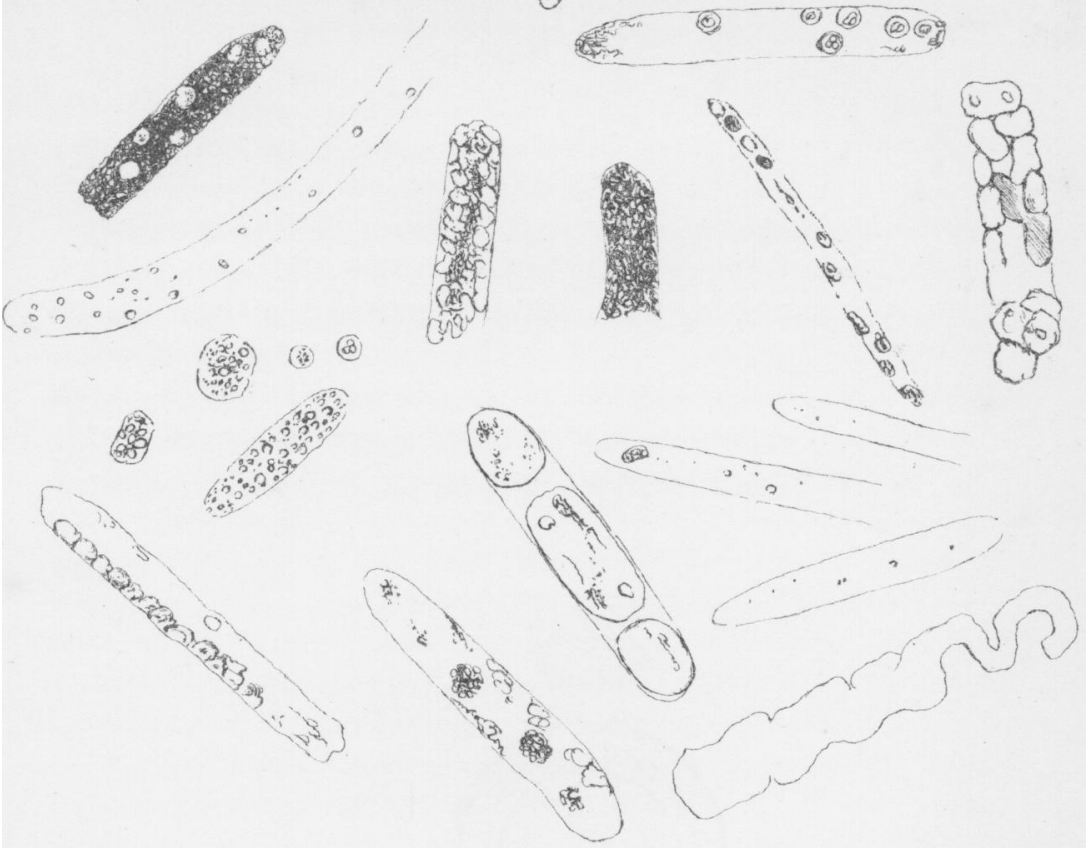

(8)

(8)

(1.8)

(92) (3)
8.8

(2)
(6) (8)

(80)
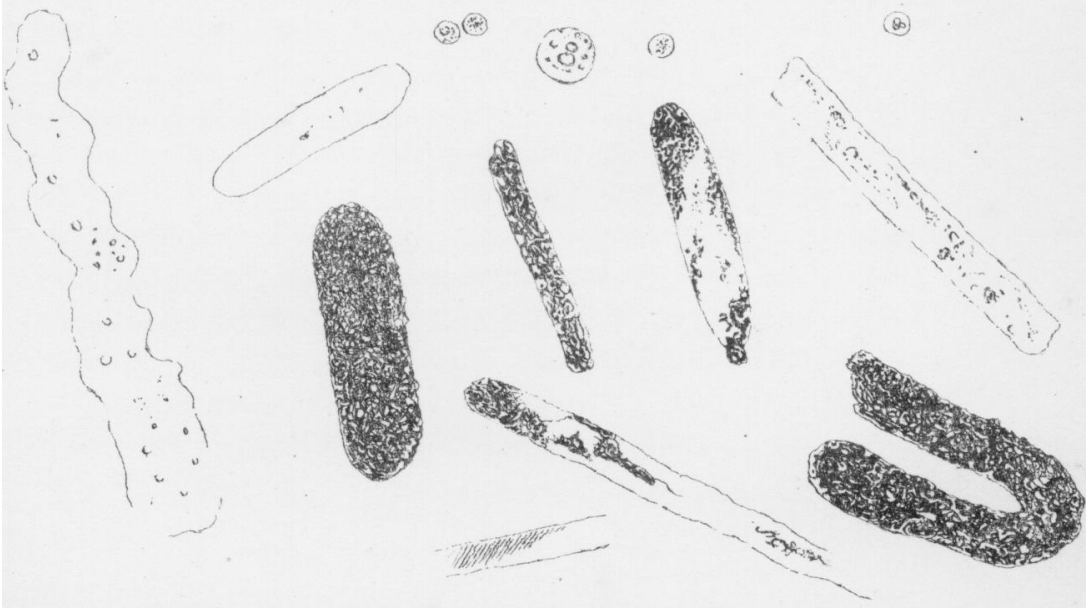

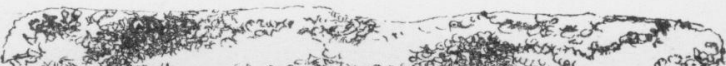

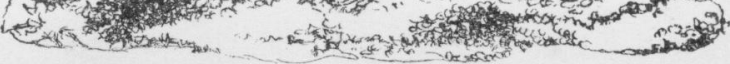

